\title{
IDAHO NATIONAL ENGINEERING LABORATORY DECONTAMINATION AND DECOMMISSIONING ROBOTICS DEVELOPMENT PROGRAM
}

Mark D. McKay 


\section{DISCLAIMER}

This report was prepared as an account of work sponsored by an agency of the United States Government. Neither the United States Government nor any agency thereof, nor any of their employees, makes any warranty, express or implied. or assumes any legal liability or responsibility for the accuracy, completeness, or usefulness of any information, apparatus, product or process disclosed, of represents that its use would not infringe privately owned rights. References herein to any specific commercial product, process, or service by trade name, trademark, manufacturer, or otherwise, does not necessarily constitute or imply its endorsement, recommendation, or favoring by the United States Government or any agency thereot. The views and opinions of authors expressed herein do not necessarily state or reflect those of the United States Government or any agency thereot. 


\title{
IDAHO NATIONAL ENGINEERING LABORATORY DECONTAMINATION AND DECOMMISSIONING ROBOTICS DEVELOPMENT PROGRAM
}

\author{
Mark D. McKay
}

April 1993

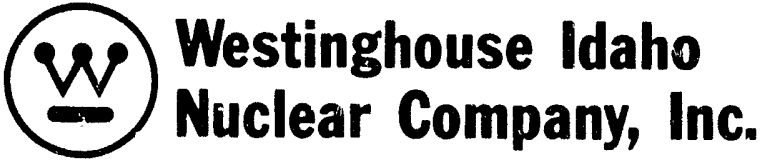

PREPARED FOR THE DEPARTMENT OF ENERGY IDAHO OPERATIONS OFFICE UNDER CONTRACT DE-AC07-84ID12435

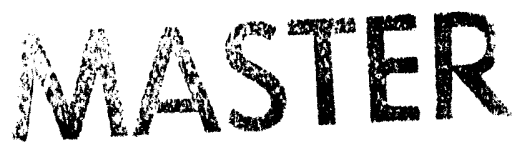




\section{IDAHO NATIONAL ENGINEERING LABORATORY DECONTAMINATION AND DECOMMISSIONING ROBOTICS DEVELOPMENT PROGRAM}

\section{TEST/DEMONSTRATION REPORT \\ FOR}

ROBOTIC PLASMA ARC CUTTING FOR D\&D APPLICATIONS
By: $\quad$ Mark D. McKay
WINCO

Date: 416193

Approved By:

R. A. Lujan, Manager

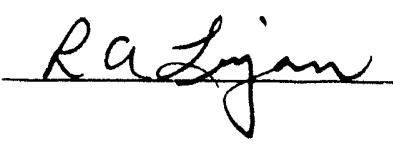

B. L. Griebenow, Manager

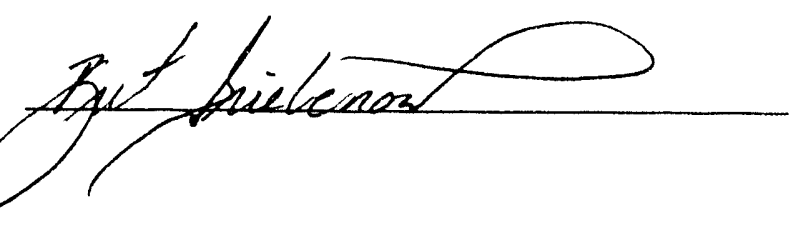




\section{INTRODUCTION}

As part of the Idaho National Engineering Laboratory (INEL) Robotics Technology Development Program (RTDP) Decontamination \& Decommissioning (D\&D) robotics program, a task was designed to integrate the plasma arc cutting technology being developed under the Waste Facility Operations (WFO) robotics program into D\&D cutting applications. The plasma arc cutting technology is based upon the use of a high energy plasma torch to cut metallic objects. Traditionally, D\&D workers removing equipment and processes from a facility have used plasma arc cutting to accomplish this task. The worker is required to don a protective suit to shield from the high electromagnetic energy released from the cutting operation. Additionally, the worker is required to don protective clothing to shield against the radioactive materials and contamination. This protective clothing can become restrictive and cumbersome to work in. Because some of the work areas contain high levels of radiation, the worker is not allowed to dwell in the environment for sustained periods of time.

To help alleviate some of the burdens required to accomplish this task, reduce or eliminate the safety hazardous to the worker, and reduce the overall cost of remediation, a program was established though the Office of Technology Development (OTD) to design and develop a robotic system capable of performing cutting operations using a plasma arc torch. Several D\&D tasks were identified having potential for use of the plasma arc cutting technology. The tasks listed below were chosen to represent common D\&D type activities where the plasma arc cutting technology can be applied.

\section{OBJECTIVES}

The D\&D Robotics Technology Development Program (RTDP) initiated a task to integrate plasma arc cutting into D\&D operations. Several D\&D tasks were identified for potential use of the plasma arc cutting technology:

1. Removal and size reduction of a simulated glove box

2. Removal and size reduction of varying sized pipes/ducts

3. Isolation and removal of "hot spots"

4. Size reduction of a vessel/tank for removal from the facility

5. Removal and size reduction of stainless steel floor and wall liners from a simulated cell section

6. Size reduction and removal of miscellaneous metal equipment (office)

Because of budget limitations three of the above tasks were chosen to demonstrate and test the D\&D robotic system. These tasks are as follows:

1. Demonstrate the capability to remove and size reduce a mockup of varying sized pipes and duct work.

2. Demonstrate the capability to isolate and remove a "hot spot" in a process line (e.g. a valve which has become inoperable and is radioactivity contaminated). 
3. Demonstrate the capability to size reduce a vessel/tank for removal from the facility.

The objective of this test was to demonstrate the ability of a robotic system to perform the above tasks.

\section{ROBOTIC SYSTEM}

The robotic system used was the system developed for the WFO demonstration scheduled for the summer of 93. The system consisted of a American Crane and Equipment Co. (ACECO) crane with a Schilling Titan 7F manipulator (arm) attached to the $\mathrm{Z}$ mast and two cameras with each 3 degrees of freedom (DOF). The crane is capable of 3 DOF $x, y$ and $z$. The Schilling arm is capable of 7 DOF (including the gripper motion, base rotate, shoulder pitch, elbow pitch, wrist pitch, wrist yaw, and wrist roll). The arm is capable of reaching approximarely 10 feet high. The system was designed to have full robotic and manual control of all $16 \mathrm{DOF}$. Figure 1 is a graphical representation of the robotic system and the D\&D mockup work cell.

\section{D\&D MOCKUP AREA WORKCELL}

The mockup area workcell consisted of a setup of three areas (refer to Figure 1):

1 vessel mockup.

2 piping, duct work and valving scheme.

3 storage box.

A large stainless steel vessel (approximately 5 feet wide by 10 feet tall) was chosen to demonstrate the capability the system has of reaching and size reducing objects that are taller than the bridge crane itself. A small mockup of a piping and duct schemes was installed into the workcell to demonstrate the ability the robotic system has to remove duct work and piping schemes of differing sizes and materials. The mockup also was setup to demonstrate the ability to isolate and remove a simulated "hot spot". A hot spot could refer to any area where process equipment has become radioactivity contaminated to the point where human contact is not possible and entry into the area is not possible until the "hot spot" has been removed. A storage box was included in the workcell to hold the cut metal pieces.

\section{TEST/DEMONSTRATION}

The demonstration was setup to demonstrate the capability of using a robotic manipulator to perform the D\&D type activities described above. A graphical workcell of the physical demonstration was created using the graphical control interface program called Workcell Simulation System (WSS) procured through DENEB Robotics Inc.. An operator then used WSS to plan and preprogram all cutting paths and also to perform collision avoidance between the robotic arm, plasma arc torch, the crane, and other items in the workcell. Several preprogrammed cutting paths were planned to guide the plasma arc torch to cut along two lines 
or trajectories, one initially along the side of the vessel and the other along the top. A cut along the side of the tank was successfully performed using the robotic preprogrammed control of the system. However, during the cut along the top of the vessel, some additional errors in the Schilling controller were discovered causing an abort of that cutting operation. Because it was not possible to correct the errors with the Schilling controller in any short period of time, a decision was made to continue the test by demonstrating the other tasks using manual control. The Schilling and crane were manually operated to successfully demonstrate the capability the system has to cut duct work, isolate a simulated hot valve and remove portions of some equipment (the vessel door). The removal of the piping schemes and the valve was delayed until Deneb could return and resolve the errors with the controller. At the time of the writing of this report, a date for Deneb to return had not been set. An attempt was made to demonstrate the valve removal and the size reduction of the piping and the vessel at a later date. The valve isolation and removal was completed successfully under tele-operated control. In addition, a second attempt at performing a full preprogrammed cut along the top of the vessel was made at this time with success. A video tape recording of the test was made and can be made available upon request.

\section{CONCLUSIONS AND RECOMMENDATIONS}

Although several errors in the controller prevented the full operation of the system during the demonstration, several observations were made while ine system was operated.

\section{PROGRAMMED CONTROL}

In D\&D cutting applications there are many situations where the geometry of the objects to be size reduced is unknown. The Deneb controller provides a graphical interface for operating the robotic equipment. To operate the robotic equipment using the controller the user must input some information in the simulated workcell which instructs the controller where to send the robot to perform the cutting operations. If information (world location, dimensions, location relative to the robot etc.) on the objects to be cut is not available to the user before hand, plotting and planning cutting paths can be difficult. Pre-programmed cutting paths are useful when the needed information on the D\&D workcell is available, when the task is repetitive and when there are several objects that are exactly the same. Preprogrammed cutting paths can also be useful when the cutting operation is difficult to perform using tele-operated control. However, the 3-D graphical representation of the workcell was found to be very useful. The workcell representation of the robotics was used to check arm configuration, tolerance, and collision avoidance when visual or video views were not available or possible.

\section{TEACHABLE ROBOTIC SYSTEMS FOR D\&D OPERATIONS}

During most D\&D cutting, disassembly and removal operations the robotic system makes contact or comes close to she equipment. Because detailed information about the equipment is not always available, the robotic system must be teachable. Teachable systems allow the user/operator to move the robotic equipment using a manual control (master control or teach pendant) to plan the cutting path. After the path is planned then the operation can be done using the automated control system. This is valuable because the operator does not need to know detailed information 
about the equipment. The operator simply uses the manual controller to touch various locations on the object to be cut.

\section{DEXTEROUS MANIPULATORS}

The deployment of tools and other end effectors in the D\&D environment requires that the manipulator be capable of a variety of different joint configurations. A manipulator with a minimum of six DOF is needed in order to maintain the level of dexterity necessary to complete the complex D\&D operations.

\section{MANIPULATOR BASE OR PLATFORM}

Because the equipment, process lines, etc. within the D\&D workcell are fixed in their location, it is necessary that the manipulator be deployed from a base that can provide full $x$ and $y$ motion and some range in the $\mathrm{z}$ direction. The manipulator must be able to reach all points within the workcell. Having the manipulator on a mobile base will facilitate this need.

\section{MANUAL OPERATION}

In addition to programmed operation, it is necessary in some cases to have the capability to operate the robotic system manually. During D\&D operations, there are cases when unexpected objects are encountered or when the object is unique enough to warrant manual operated cutting. During the test/demonstration, manual operation was found to be best suited for picking up and transferring cut pieces and/or objects.

\section{FORCE REFLECTIVE OPERATIONS}

Force reflective feedback to the controller is necessary when performing plasma arc cutting. To maximize the cutting operation, the plasma arc cutter was setup with an adjustable standoff during this test. The standoff is required to maintain contact with the cutting surface at all times. A manipulator equipped with force feedback can be used to maintain a constant force against the cutting surface at all times during the cutting operations. The Schilling manipulator in this test was equipped with a force reflective transducer. However, the control algorithm did not respond correctly when the maximum force limit was reached and, as such, the force limiting routine was nol used.

\section{$7 \quad$ CONTOUR FOLLOWING}

Many objects and equipment that require cutting have irregular shapes and many surfaces, when cutting, will change because of heat. Automated cutting along uneven and irregular surfaces can be very difficult where precise surface information is not known or the surface changes dynamically. To perform this type of cutting, real time contour following is strongly recommended. Contour following is the ability to maintain a constant force or exert a constant pressure against any surface while moving along that surface, without needing complex geometry information.

\section{END-EFFECTORS}

The cutting and other tools needed for D\&D tasks must be capable of remote change-out. Many different tasks can be performed by the same robotic equipment during D\&D operations. In order 
to achieve this the manipulator must be capable of changing end-effectors, for example, from the plasma arc torch to an impact wrench.

9 CAMERAS

To minimize the effort required by the operator, the camera systems should follow the end of the manipulator (end-effector). This gives the operator constant view of the cutting areas without requiring the operator(s) to perform this task. The system test does have camera following capabilities. However, as stated the system was not fully operational at the time of the test. 


\section{REFERENCES}

Integration of The RTDP Decontamination and Decommissioning Effort with the RTDP Remote Size Reduction Activities at INEL - KMC-3-5-92 
Robotics Decontamination and Decommissioning

April 6, 1993

TTP \# 4232-01, Subtask \#3 Report

Page 07

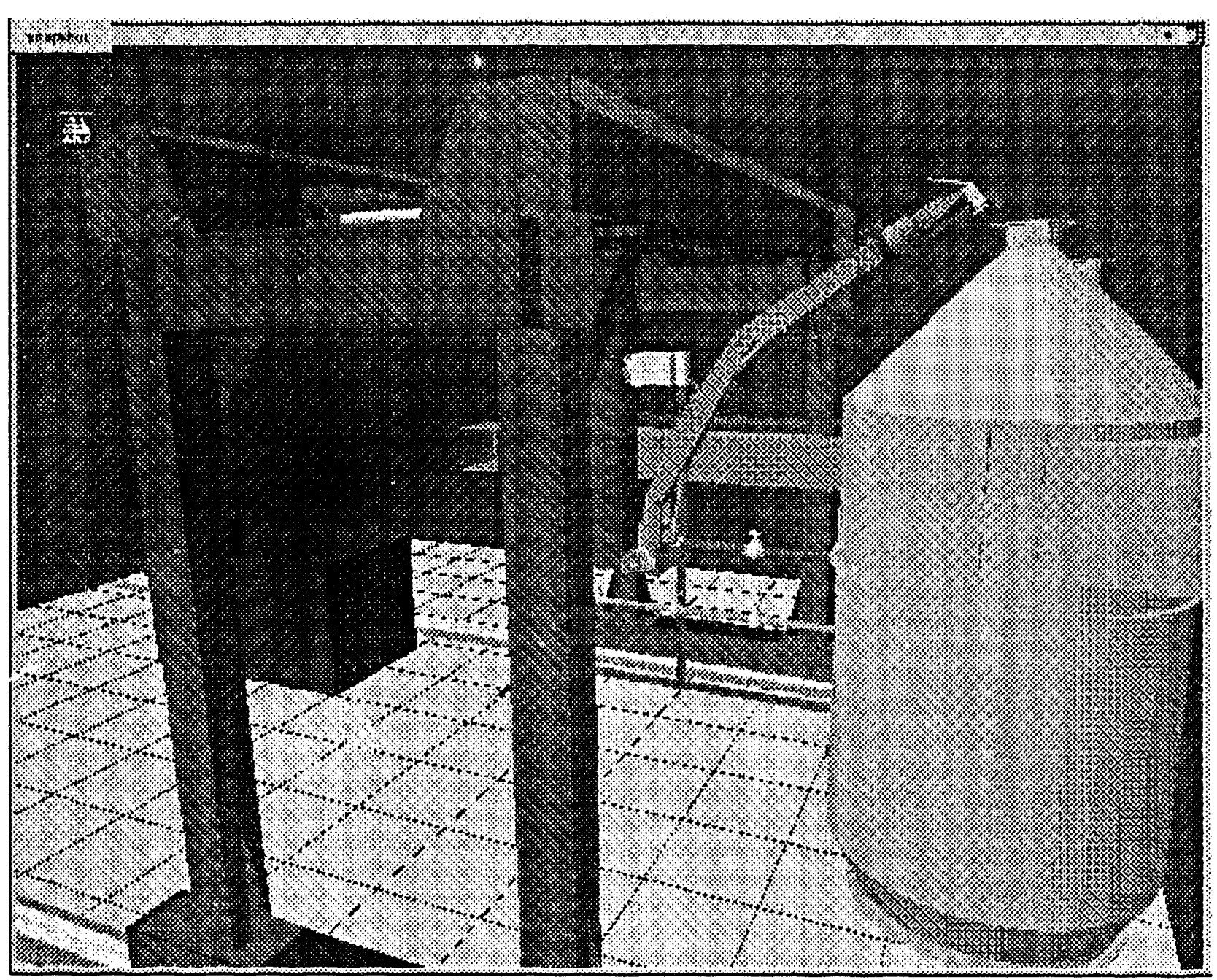

Figure I. 

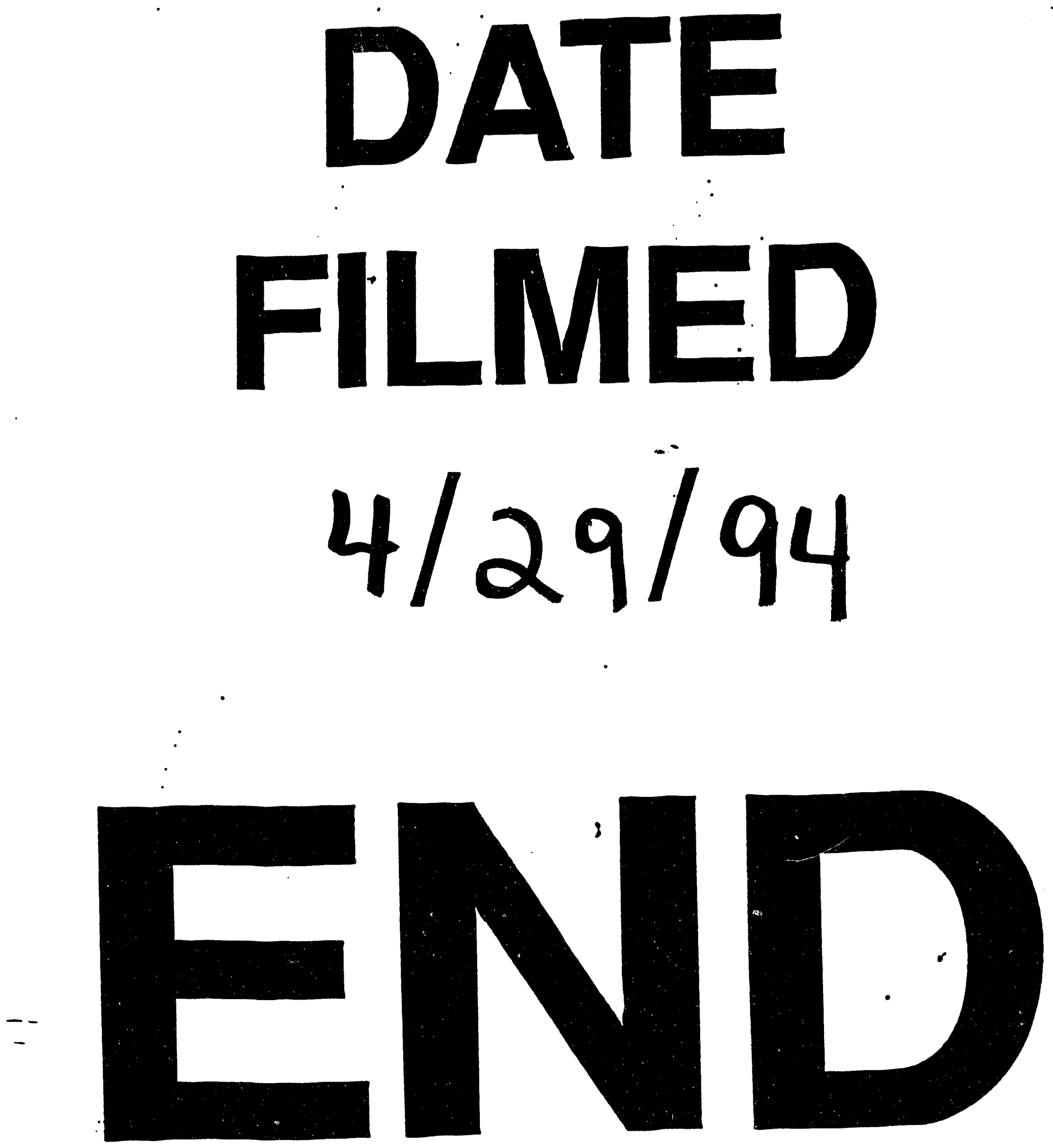